\section{Kidney \\ Blood Pressure Research}

\title{
Incidence of Hypersensitivity Reactions During Hemodialysis
}

\author{
Raquel Esteras ${ }^{a} \quad$ Juan Martín-Navarro ${ }^{b} \quad$ Gabriel Ledesma $^{c}$ \\ Raúl Fernández-Prado ${ }^{a}$ Gilda Carreño ${ }^{c}$ Melissa Cintra ${ }^{d}$ Ignacio Cidraque \\ Ignacio Sanz ${ }^{f} \quad$ Blanca Tarragón ${ }^{f} \quad$ Simona Alexandru ${ }^{g} \quad$ Mónica Milla ${ }^{h}$ \\ Elena Astudilloi Emilio Sánchezi Sebastian Masa Rafael Díaz Tejeiroj \\ Alberto Ortiz ${ }^{a}$ Rafael Sánchez ${ }^{c} \quad$ Emilio González-Parra ${ }^{a}$ \\ aHospital Fundación Jiménez Díaz and FRIAT, Madrid, bHospital del Tajo, Madrid, 'Hospital Universitario \\ La Paz, Madrid, dHospital Virgen de Macarena, Sevilla, eHospital Vall d’Hebron, Barcelona, ${ }^{\mathrm{f}} \mathrm{Hospital}$ \\ Puerta de Hierro, Madrid, 9Hospital Rey Juan Carlos Móstoles, Madrid, hHospital Doce de Octubre, \\ Madrid, iHospital Universitario Central de Asturias, Oviedo, jHospital Virgen de la Salud, Toledo, Spain
}

\section{Key Words}

Hemodialysis - Dialyzer - Acute reaction - Allergic reaction - Polysulfone - Polynephron • Membrane

\begin{abstract}
Background/Aims: A recent alert from Spanish health authorities warned of a higher incidence of reported hypersensitivity reactions to hemodialysis membranes with polysulfone, in the 2017 review of acute reactions to dialyzers found only published reports in the $21^{\text {st }}$ century on polysulfone and its derivatives. The aim is to assess/evaluate the current incidence and characteristics of hypersensitivity reactions in hemodialysis patients. Methods: A retrospective multicentre study in 9 Spanish hospitals evaluated patients in whom a hypersensitivity reaction required a change in dialyzer membrane. Results: A total of 37 patients out of 1561 (2.37\%) had hypersensitivity reactions and clinical, epidemiological and analytical data were available for 33 patients $(2.11 \%)$. The membranes involved were polysulfone $(n=23)$, polynephron $(n=8)$, polyethersulfone $(n=1)$ and polyacrylonitrile $(n=1)$. This distribution reflected the frequency of use of membranes in the participating dialysis units. The reactions were described as type $A$ in 18 cases and type $B$ in 15 cases. There were no significant differences between the two types in clinical symptoms, the composition of the membrane involved, the method of sterilization, the season, or the time during the session in which they occurred. The most frequent symptom was dyspnea/breathlessness (64\% of reactions). Eosinophilia was common (74\%). $54 \%$ of the reactions occurred within the first 30 minutes of hemodialysis, $64 \%$ occurred during the first year of dialysis, and $54 \%$ required discontinuation of dialysis session. Cellulose
\end{abstract}




\section{Kidney Blood Pressure Research}

Kidney Blood Press Res 2018;43:1472-1478

\begin{tabular}{l|l}
\hline DOI: 10.1159/000493662 & C 2018 The Author(s). Published by S. Karger AG, Base
\end{tabular}

Publisnea onine: ZI september, 2018 www.karger.com/kbr

Esteras et al.: Hypersensitivity in Hemodialysis

triacetate was used as an alternative dialyzer in $78 \%$ of the cases. Conclusion: The incidence of hypersensitivity reactions was in the range found in reports from 20 years ago and is observed associated with synthetic membranes, not just polysulfones. Cellulose triacetate appears to be a good alternative for these patients.

\section{Introduction}

Hemodialysis is an extracorporeal renal replacement technique in which the patient's blood is in direct contact with different materials. The hypersensitivity reactions associated with dialysis membranes have long been known [1-7], although the causes are not well characterized $[8,9]$. The complexity of dialysis systems, which are composed of a large number of different materials, makes it difficult to to accurately determine the agent that causes a hypersensitivity reaction in a specific patient. Hypersensitivity reactions have historically been classified as type A and type B reactions [4, 5]. Type A reactions start in the first few minutes after initiation of dialysis and clinical manifestations are variable. They may be IgEdependent (anaphylactic reactions, e.g. triggered by ethylene oxide, formaldehyde, latex, chlorhexidine, intravenous iron, erythropoiesis-stimulating agents or heparin) $[10,11]$, or IgE-independent (anaphylactoid reactions, e.g. those triggered by opioids, iodine contrasts, the AN69 membrane and non-steroidal anti-inflammatory agents)[12, 13]. Type B reactions are more frequent, start later in the hemodialysis session, and have milder symptoms. They are thought to be associated with the release of histamine, leukotrienes and bradykinin and are associated to the use of less biocompatible cellulosic membranes.

Membrane composition (from cellulose to synthetic membranes), sterilization methods (removal of ethylene oxide) and other materials in the dialyzer and tubing (glue, binders, plastics, latex, silicones, etc.) have evolved to improve biocompatibility. But despite this improved biocompatibility, no clear decrease in hypersensitivity reactions has been observed $[6,7,11,14,15]$. However, the literature on incidence of hypersensitivity reactions is old. A recent (2017) review on the subject cited incidence data published before 1996, when many potential triggers are no longer present today (as widespread use of cellulose or AN-69 membranes and ethylene oxide sterilization) [16]. In 1996, a prospective French study of 1573 patients reported an annual incidence of $0.17 / 1,000$ sessions per year for cellulose and 4.2/1, 000 sessions per year for synthetic membranes [15]. Some patients had several reactions, and reactions occurred in $1.3 \%$ of patients. However, the incidence for synthetic membranes was influenced by a very high incidence in patients on AN69 membranes taking ACE inhibitors $(7.2 \%$ of patients had reactions vs $1.6 \%$ of patients with other synthetic dialysis membranes) [15]. In recent years, there has been a wave of reports of cases of hypersensitivity to dialyzers, many of them related to polysulfones [17-24]. Concern have been expressed that the high number of recent reports indicates an increased incidence, related to changes in the materials used to manufacture synthetic membranes $[6,18,21,22$, $25,26]$. In this regard, Spanish health authorities issued in 2015 an alert on an increase in the incidence of reported hypersensitivity reactions to polysulfone membranes [27]. In a recent review of 2017, Boer et al. found a total of 30 cases of acute reactions to dialyzer membranes published in the $21^{\text {st }}$ century: all of them were with membranes from the polyarylsulfonate family (polysulfone and polyethersulfone), which raises the concern that, among modern membranes, only those made of polysulfone and derivatives cause acute reactions [24]

We have now conducted a multicenter study to describe the incidence and clinical presentation of hypersensitivity reactions diagnosed by nephrologists, the associated factors and the materials and techniques involved, to improve our understanding of the current incidence and presentation of hypersensitivity reactions to dialysis. 


\section{Kidney Blood Pressure Research}

\begin{tabular}{l}
\hline Kidney Blood Press Res 2018;43:1472-1478 \\
\hline \begin{tabular}{l|l} 
DOI: 10.1159/000493662 & @ 2018 The Author(s). Published by S. Karger AG, Basel \\
Publisned online: 21 September, 2018 & www.karger.com/kbr
\end{tabular} \\
\hline
\end{tabular}

Esteras et al.: Hypersensitivity in Hemodialysis

\section{Materials and Methods}

\section{Study population}

Retrospective multicenter observational study in adult dialysis units at 9 Spanish hospitals including all patients diagnosed with a dialysis membrane hypersensitivity reaction from August 2015 to August 2017.

\section{Case definition}

The case definition included a clinical diagnosis of symptoms occurring during the dialysis session, for which no other cause was found; which led the physician to prescribe a change in dialyzer, improving when the material in the dialyzer membrane was changed. The change in dialyzer had to be made within the same session in which symptoms developed or in the next session. There was no threshold for severity of symptoms other than the clinician's decision to change the membrane. Being a retrospective study, this inclusion criterion was not expected to influence the case definition. Characterization as type A or type B reactions was made at each center by the clinician on duty.

\section{Data collection}

Cases were identified through a survey in each center. All nine centers contacted responded the survey. Cases were identified by an exhaustive review of electronic databases. Thirty-seven patients were identified who were prescribed a change in dialyzer because for suspected hypersensitivity reaction and symptoms improved on the new dialyzer. Only for 33 of them had the full dataset required to be evaluated. In four patients, detailed data for the episode were missing and were not analyzed. In this sense, since this is a retrospective study, it was not possible to guarantee the exhaustiveness of recording and registering of the characteristics of the episodes in the databases. However, the change of dialyzer is an event that is well collected in dialysis units using electronic databases, where the dialyzer used must be recorded.

The following data were obtained from electronic records: age, sex, hemodialysis vintage, hemodialysis technique and season in which the reaction occurred, clinical symptoms, timing of onset, responsible membrane, substitution membrane, whether symptoms persisted on another synthetic membrane and if the patient required treatment with a cellulosic membrane. Eosinophilia was defined as more than 500 eosinophils per $\mu \mathrm{l}$ during the episode.

\section{Outcome}

The primary objective was to define the clinical characteristics of the episodes, the involved dialyzers and their frequency.

\section{Statistical analysis}

Categorical variables were expressed as frequencies and percentages and compared with the Fisher's exact probability test. To compare more than two categorical variables, the chi-square (v2) test was used. Numerical categories were expressed as mean \pm SD and compared using the Mann-Whitney U test. Statistical analyses were performed with STATA software for Windows, version 12.0 (Statacorp LP, College Station, TX, USA) with two-sided hypothesis testing and a $\mathrm{P}<0.05$ as the criteria for statistical significance.

\section{Results}

During the study period, a total of 1561 patients were dialyzed in the nine dialysis units, using polysulfone (PS, $n=893,57 \%$ ), polynephron (PN, $n=407,26 \%$ ) or other membranes: polyethersulfone (PES), polyacrylonitrile (PAN) and others. All dialyzers were sterilized by steam or gamma rays.

Hypersensitivity episodes occurred in 37 patients, of whomthere were enough data available for 33 (Table 1). Membranes involved in hypersensitivity episodes included PS $(n=23,70 \%), P N(n=8,22 \%)$, PES $(n=1,3 \%)$ and PAN $(n=1,3 \%)$. The reaction was described as type $A$ in 18 cases (PS in 13, PN in 3, PES in 1 and PAN in 1) and type B in 15 cases (PS in $10, \mathrm{PN}$ in 5 ). There were no significant differences between the basic clinical characteristics 


\section{Kidney Blood Pressure Research}

analysed between type $A$ and type $B$, except for the dialysis vintage, which was lower for type B reactions, being 1 year in $64 \%$ of patients in the overall population (Table 1).

Table 2 shows the symptoms used to diagnose hypersensitivity and trigger membrane change. The onset of symptoms was within 30 minutes in around $55 \%$ of patients. The range of symptoms was wide and the presentation very variable. The most frequent reaction was dyspnea in $64 \%$ of patients, followed by hypotension (33\%). The only statistically significant difference between reactions classified as type $A$ and type $B$ by nephrologists was nonspecific symptoms, which were unique to type $B$ reactions.

The reaction was severe enough to discontinue the dialysis session in $55 \%$ of patients, but there were no differences in severity between type $\mathrm{A}$ and type $B$ reactions (Table 3 ). In terms of laboratory values, eosinophilia was present in $74 \%$ of patients. It was speculated that these reactions could occur more frequently in spring, which corresponds to maximum allergenic activity. This could not be confirmed by our analysis, as the episodes were distributed throughout the year and only $21.2 \%$ of episodes occurred in spring.
Kidney Blood Press Res 2018;43:1472-1478

\begin{tabular}{l|l}
\hline DOI: 10.1159/000493662 & (C) 2018 The Author(s). Published by S. Karger AG, Basel
\end{tabular} Published onlıne: 21 September, 2018 www.karger.com/kbr

Table 1. Clinical characteristics of patients according to the type of hypersensitivity reaction

\begin{tabular}{lcccc}
\hline Variable & Total & $\begin{array}{c}\text { Type A } \\
(\mathrm{n}=18)\end{array}$ & $\begin{array}{c}\text { Type B } \\
(\mathrm{n}=15)\end{array}$ & $\mathrm{P}$ \\
\hline Age (years) & $64.6 \pm 15.7$ & $64.0 \pm 17.4$ & $65.3 \pm 14.1$ & $\mathrm{Ns}$ \\
Male sex, n (\%) & $16(48.5 \%)$ & $10(55.6 \%)$ & $6(40.0 \%)$ & $\mathrm{Ns}$ \\
Dialysis vintage, n (\%) & $21(63.6 \%)$ & $15(83.3 \%)$ & $6(40.0 \%)$ & 0.023 \\
$<1$ year & $2(6.1 \%)$ & $1(5.6 \%)$ & $1(6.7 \%)$ & \\
1-2 years & $1(3.0 \%)$ & $0(0.0 \%)$ & $1(6.7 \%)$ & \\
2-3 year & $9(27.3 \%)$ & $2(11.1 \%)$ & $7(46.7 \%)$ & \\
$>$ 3 year & $23(69.7 \%)$ & $13(72.4 \%)$ & $10(66.7 \%)$ & \\
Membranes & $8(24.3 \%)$ & $3(16.6 \%)$ & $5(33.3 \%)$ & \\
Polysulfone & $1(3.0 \%)$ & $1(5.5 \%)$ & $0(0.0 \%)$ & \\
Polynephron & $1(3.0 \%)$ & $1(5.5 \%)$ & $0(0.0 \%)$ & Ns \\
Polyethersulfone & & & & \\
Polyacrylnitrile & $10(30.3 \%)$ & $5(27.6 \%)$ & $5(33.3 \%)$ & \\
Sterilization procedure & $23(69.7 \%)$ & $13(72.4 \%)$ & $10(66.7 \%)$ & \\
Gamma Irradiation & & & & \\
Steam & & & & \\
& & & & \\
& & & & \\
\end{tabular}

Table 2. Symptoms that caused the membrane change for reactions classified as type A or B by nephrologists

\begin{tabular}{lcccc}
\hline Variable, $\mathrm{n}(\%)$ & $\begin{array}{c}\text { Total } \\
(\mathrm{n}=33)\end{array}$ & $\begin{array}{c}\text { Type A } \\
(\mathrm{n}=18)\end{array}$ & $\begin{array}{c}\text { Type B } \\
(\mathrm{n}=15)\end{array}$ & $\mathrm{P}$ \\
\hline Onset <30 min, n (\%) & $18(54.5 \%)$ & $12(66.7 \%)$ & $6(40.0 \%)$ & $\mathrm{ns}$ \\
Dyspnea & $21(63.6 \%)$ & $13(72.2 \%)$ & $8(53.3 \%)$ & $\mathrm{ns}$ \\
Vomiting & $3(9.1 \%)$ & $2(11.1 \%)$ & $1(6.7 \%)$ & $\mathrm{ns}$ \\
Low level of awareness & $1(3.0 \%)$ & $1(5.6 \%)$ & $0(0.0 \%)$ & $\mathrm{ns}$ \\
Chest pain & $3(9.1 \%)$ & $2(11.1 \%)$ & $1(6.7 \%)$ & $\mathrm{ns}$ \\
Hypotension & $9(27.3 \%)$ & $4(22.2 \%)$ & $5(33.3 \%)$ & $\mathrm{ns}$ \\
Cough & $2(6.1 \%)$ & $0(0.0 \%)$ & $2(13.3 \%)$ & $\mathrm{ns}$ \\
Hives & $4(12.1 \%)$ & $1(5.6 \%)$ & $3(20.0 \%)$ & $\mathrm{ns}$ \\
Digestive symptoms & $3(9.1 \%)$ & $0(0.0 \%)$ & $3(20.0 \%)$ & $\mathrm{ns}$ \\
Non-specific symptoms & $4(12.1 \%)$ & $0(0.0 \%)$ & $4(26.7 \%)$ & 0.033 \\
Headache & $4(12.1 \%)$ & $2(11.1 \%)$ & $2(13.3 \%)$ & $\mathrm{ns}$ \\
Shivering & $1(3.0 \%)$ & $1(5.6 \%)$ & $0(0.0 \%)$ & $\mathrm{ns}$ \\
\hline
\end{tabular}

Table 3. Additional data for reactions classified as type A or B by nephrologists

\begin{tabular}{lcccc}
\hline Variable, n (\%) & $\begin{array}{c}\text { Total } \\
(\mathrm{n}=33)\end{array}$ & $\begin{array}{c}\text { Type A } \\
(\mathrm{n}=18)\end{array}$ & $\begin{array}{c}\text { Type B } \\
(\mathrm{n}=15)\end{array}$ & $\mathrm{P}$ \\
\hline Discontinuation of dialysis session & $18(54.5 \%)$ & $8(44.4 \%)$ & $10(66.7 \%)$ & $\mathrm{ns}$ \\
Eosinophilia & $20(74.1 \%)$ & $11(68.8 \%)$ & $9(81.8 \%)$ & $\mathrm{ns}$ \\
Month & $7(21.2 \%)$ & $5(27.8 \%)$ & $2(13.3 \%)$ & $\mathrm{ns}$ \\
$\quad$ June-July-August & $10(30.3 \%)$ & $5(27.8 \%)$ & $5(33.3 \%)$ & \\
Sept-Oct-Nov & $9(27.3 \%)$ & $4(22.2 \%)$ & $5(33.3 \%)$ & \\
Dec-Jan-Feb & $7(21.2 \%)$ & $4(22.2 \%)$ & $3(20.0 \%)$ & \\
March-April-May & & & & \\
& & & & \\
Alternative Dialyzer & $25(78.1 \%)$ & $11(64.7 \%)$ & $14(93.3 \%)$ & \\
Cellulose triacetate & $2(6.2 \%)$ & $1(5.9 \%)$ & $1(6.7 \%)$ & \\
Polyacrylonitrile & $1(3.1 \%)$ & $1(5.9 \%)$ & $0(0.0 \%)$ & \\
Polyethersulfone & $2(6.2 \%)$ & $2(11.8 \%)$ & $0(0.0 \%)$ & \\
Polycarbonate & $2(6.2 \%)$ & $2(11.8 \%)$ & $0(0.0 \%)$ & \\
Polysulfone/Helixone & $1(3.1 \%)$ & $1(5.9 \%)$ & $0(0.0 \%)$ & \\
Unknown & & & & \\
\hline
\end{tabular}

\section{Switch dialyzer}

The alternative dialyzer after the event was cellulose triacetate in $78 \%$ of the cases (Table 3). However, for the reactions classified as type A, the switch dialyzer was another synthetic membrane in $35 \%$ of cases. 


\section{Kidney Blood Pressure Research}

Kidney Blood Press Res 2018;43:1472-1478

\begin{tabular}{l|l}
\hline DOI: $10.1159 / 000493662$ & C 2018 The Author(s). Published by S. Karger AG, Basel
\end{tabular}

Published onlıne: 21 September, 2018 www.karger.com/kbr

Esteras et al.: Hypersensitivity in Hemodialysis

\section{Discussion}

The main finding is an estimate of the incidence of acute dialyzer reactions in the $21^{\text {st }}$ century. Prior data were obtained more than 20 years ago when the mix of dialyzer materials was different. The incidence of hypersensitivity reactions was found to be in the range reported 20 years ago and they occurred with several synthetic membranes, with a frequency reflecting the prevalence of each membrane. Our results are paradigm-changing by demonstrating biased reporting that led prior authors to conclude, based on a literature review of case reports performed in 2017, that polyarylsulfone membranes are the only synthetic membranes inducing reactions in the $21^{\text {st }}$ century, triggering a warning by Spanish Health authorities specifically for polysulfone membranes [24].

A recent increase in the number of reports on hypersensitivity reactions has created alarm and caused a warning by Spanish health authorities on the risks of polysulfone membranes $[17-23,27]$. However, our findings indicate that the percentage of patients with reactions was in the range reported for synthetic membranes twenty years ago [15] and the episodes occurred with different synthetic membranes (PS, PN, PES, PAN) in frequencies reflecting their share of the membranes used in the participating dialysis units. The prevalence of hypersensitivity reactions in our study $(2.37 \%$ of patients) was significantly higher than in a prior publication studying 1536 patients $(p<0.05)$ [15]. However, in a sensitivity analysis considering only the reactions for which complete information was available, differences were no longer significant. Furthermore, these frequencies did not differ from the $1.6 \%$ reported for non-AN69 artificial membranes [15]. These data do not support the current existence of a peak in the occurrence of hypersensitivity reactions to PS. However, they do not exclude the past occurrence of mini-epidemics of such episodes.

The reactions observed in the current study lacked a clear and recognizable clinical pattern. Most symptoms occurred in the first half hour of dialysis and were very variable, from dyspnea and hypotension to headache, as recently reviewed [24]). The only common clinical characteristic was disappearance of symptoms upon change of the dialysis membrane composition. In the vast majority of the cases, synthetic membranes were replaced by a cellulose triacetate membrane. The warning from the Spanish health authorities [27] may have contributed to assigning non-specific symptoms to hypersensitivity, triggering a change of dialyzer and confirmation of the diagnosis if symptoms disappeared. In turn, this widespread awareness may have contributed to increase the number of reported cases.

The simple solution of changing the membrane has hampered research into triggering factors [21]. In the past, ethylene oxide sterilization was considered a potential cause [15, 26]. However, it is no longer used in Spain and membranes sterilized by either steam or gamma rays were involved in hypersensitivity reactions in the present report. Hypersensitivity reactions to dialysis membranes may not depend on the main membrane component, but on additional molecules that differ according to the manufacture procedure $[18,20$, 21]. Thus, molecules that may theoretically trigger hypersensitivity reactions include polyvinylpyrrolidone (PVP) [22], bisphenol A (BPA) [18], parabens, carbamates, thiurams, formaldehydesdes, rubber, plastics, epoxy resins used as glue, and polyurethanes. These molecules may change the antigenic properties of adsorbed endogenous proteins [28]. Additional dialyzer components, such as PVP and BPA are not exclusive to either polysulfone membranes or a single manufacturer and the lack of information in the technical data sheets does not allow for a reliable characterization their presence in dialyzers.

A number of limitations should be acknowledged. It was a retrospective study and there is the possibility of underreporting. However, the widespread use of prospectively filled electronic records allowed the easy identification of cases. Furthermore, any underreporting would have been expected to be randomly distributed among the different membranes. Additionally, the characterization of reactions into type A or type B was made by the nephrologist on duty and the lack of difference in the timing of type A and B reactions 


\section{Kidney \\ Bloód Pressure Research}

observed suggests that under routine clinical practice conditions, nephrologists have difficulties in classifying the events into the two types.

In conclusion, hypersensitivity reactions occur with any synthetic membrane and their frequency is in the range reported twenty years ago. The recent increase in published cases related to polysulfone membranes does not appear to correspond to a real increase in cases. Cellulose triacetate appears to be a good alternative for these patients.

\section{Acknowledgements}

EGP research is funded by the Spanish government: FIS PI16/01298 and REDINREN RD016/0009.

\section{Disclosure Statement}

The authors declare the following potential conflict of interest: AO has received speaker fees from Fresenius Medical Care, EGP has received speaker fees from Nipro.

\section{References}

1 Poothullil J, Shimizu A, Day RP, Dolovich J: Anaphylaxis from the product(s) of ethylene oxide gas. Ann Intern Med 1975;82:58-60.

-2 Villarroel F, Ciarkowski AA: A survey on hypersensitivity reactions in hemodialysis. Artif Organs 1985;9:231-238.

- Villarroel F: Incidence of hypersensitivity in hemodialysis. Artif Organs 1984;8:278-280.

4 Daugirdas JT, Ing TS, Roxe DM, Ivanovich PT, Krumlovsky F, Popli S, McLaughlin MM: Severe anaphylactoid reactions to cuprammonium cellulose hemodialyzers. Arch Intern Med 1985;145:489-494.

-5 Daugirdas JT, Ing TS: First-use reactions during hemodialysis: a definition of subtypes. Kidney Int Suppl 1988;24:S37-43.

-6 Tielemans C, Madhoun P, Lenaers M, Schandene L, Goldman M, Vanherweghem JL: Anaphylactoid reactions during hemodialysis on AN69 membranes in patients receiving ACE inhibitors. Kidney Int 1990;38:982984.

7 Butani L, Calogiuri G: Hypersensitivity reactions in patients receiving hemodialysis. Ann Allergy Asthma Immunol 2017;118:680-684.

8 Canaud B, Aljama P, Tielemans C, Gasparovic V, Gutierrez A, Locatelli F: Pathochemical toxicity of perfluorocarbon-5070, a liquid test performance fluid previously used in dialyzer manufacturing, confirmed in animal experiment. J Am Soc Nephrol 2005;16:1819-1823.

-9 Cheung AK: Biocompatibility of hemodialysis membranes. J Am Soc Nephrol 1990;1:150-161.

10 Maurice F, Rivory JP, Larsson PH, Johansson SG, Bousquet J: Anaphylactic shock caused by formaldehyde in a patient undergoing long-term hemodialysis. J Allergy Clin Immunol 1986;77:594-597.

11 Ebo DG, Bosmans JL, Couttenye MM, Stevens WJ: Haemodialysis-associated anaphylactic and anaphylactoid reactions. Allergy 2006;61:211-220.

12 Verresen L, Fink E, Lemke HD, Vanrenterghem Y: Bradykinin is a mediator of anaphylactoid reactions during hemodialysis with AN69 membranes. Kidney Int 1994;45:1497-1503.

13 Schulman G, Hakim R, Arias R, Silverberg M, Kaplan AP, Arbeit L: Bradykinin generation by dialysis membranes: possible role in anaphylactic reaction. J Am Soc Nephrol 1993;3:1563-1569.

14 Centers for Disease Control (CDC): Update: acute allergic reactions associated with reprocessed hemodialyzers--United States, 1989-1990. MMWR Morb Mortal Wkly Rep 1991;40:147, 153-154.

15 Simon P, Potier J, Thebaud HE: [Risk factors for acute hypersensitivity reactions in hemodialysis]. Nephrologie 1996;17:163-170. 


\section{Kidney \\ Blood Pressure Research}

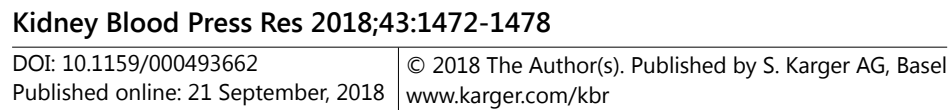

Esteras et al.: Hypersensitivity in Hemodialysis

16 Saha M, Allon M: Diagnosis, Treatment, and Prevention of Hemodialysis Emergencies. Clin J Am Soc Nephrol 2017;12:357-369.

17 González Sanchidrián S, Labrador Gómez PJ, Marín Álvarez JP, Jiménez Herrero MC, Castellano Cerviño I, Gallego Domínguez S, Sánchez-Montalbán JM, Deira Lorenzo J, Davin Carrero E, Planco Candelario S, Gómez-Martino Arroyo JR: Reacción a membranas sintéticas en hemodiálisis. Nefrología 2016;36:707-709.

18 Martín-Navarro JA, Gutiérrez-Sánchez MJ, Petkov-Stoyanov V: Hypersensitivity to synthetic hemodialysis membranes. Nefrologia 2014;34:807-808.

19 Arenas MD, Gil MT, Carretón MA, Moledous A, Albiach B: [Adverse reactions to polysulphone membrane dialyzers durind hemodialysis]. Nefrologia 2007;27:638-642.

20 Ohashi N, Yonemura K, Goto T, Suzuki H, Fujigaki Y, Yamamoto T,Hishida A: A case of anaphylactoid shock induced by the BS polysulfone hemodialyzer but not by the F8-HPS polysulfone hemodialyzer. Clin Nephrol 2003;60:214-217.

-21 Sánchez-Villanueva RJ, González E, Quirce S, Díaz R, Alvarez L, Menéndez D, Rodríguez-Gayo L, Bajo MA, Selgas R: Hypersensitivity reactions to synthetic haemodialysis membranes. Nefrologia 2014;34:520-525.

22 Bacelar Marques ID, Pinheiro KF, de Freitas do Carmo LP, Costa MC, Abensur H: Anaphylactic reaction induced by a polysulfone/polyvinylpyrrolidone membrane in the 10th session of hemodialysis with the same dialyzer. Hemodial Int 2011;15:399-403.

23 Huang WH, Lee YY, Shih LC: Delayed near-fatal anaphylactic reaction induced by the F10-HPS polysulphone haemodialyser. Nephrol Dial Transplant 2008;23:423-424.

24 Boer WH, Liem Y, de Beus E, Abrahams AC: Acute reactions to polysulfone/polyethersulfone dialysers: literature review and management. Neth J Med 2017;75:4-13.

25 Alvarez-de Lara MA, Martín-Malo A: Hypersensitivity reactions to synthetic haemodialysis membranes an emerging issue? Nefrologia 2014;34:698-702.

-26 Konishi S, Fukunaga A, Yamashita H, Miyata M, Usami M: Eluted substances from hemodialysis membranes elicit positive skin prick tests in bioincompatible patients. Artif Organs 2015;39:343-351.

27 Agencia Española de Medicamentos y Productos Sanitarios. Alerta de productos sanitarios 253/2015: Aumento en las reacciones de hipersensibilidad y similares a la hipersensibilidad relacionadas con el uso de dializadores FX Cordiax de alta permeabilidad y hemofiltros Fx Cordiax. URL: http://www.caib.es/sites/ productessanitaris/es/d/alerta_ps-253_aumento_en_las_reacciones_de_hipersensibilidad_y_similares_a_ la_hipersensibilidad_relacionadas_con_el_uso_de_los_dializadores_fx_cordiax_de_alta_permeabilidad_y_ hemofiltros_fx_cordiax_fabricados_por_fresenius_medical_care_ag_kgaa_alemania-85185/.

28 Urbani A, Sirolli V, Lupisella S, Levi-Mortera S, Pavone B, Pieroni L, Amoroso L, Di Vito R, Bucci S, Bernardini $\mathrm{S}$, Sacchetta P, Bonomini M: Proteomic investigations on the effect of different membrane materials on blood protein adsorption during haemodialysis. Blood Transfus 2012;10:S101-112. 